\title{
The Effect of Nitrogen Ion Implantation on the Surface Properties of Ti6Al4V Alloy Coated by a Carbon Nanolayer
}

\author{
Petr Vlcak, ${ }^{1}$ Frantisek Cerny, ${ }^{1}$ Zdenek Weiss, ${ }^{2}$ Stanislav Danis, ${ }^{3}$ Josef Sepitka, ${ }^{1}$ \\ Zdenek Tolde, ${ }^{1}$ and Vladimir Jech $^{1}$ \\ ${ }^{1}$ Faculty of Mechanical Engineering, Czech Technical University in Prague, 16607 Prague, Czech Republic \\ ${ }^{2}$ Application Center Prague, LECO Instrument Plzen spol. s. r.o., 19000 Prague, Czech Republic \\ ${ }^{3}$ Faculty of Mathematics and Physics, Charles University in Prague, 12116 Prague, Czech Republic
}

Correspondence should be addressed to Petr Vlcak; petr.vlcak@fs.cvut.cz and Frantisek Cerny; frantisek.cerny@fs.cvut.cz

Received 20 September 2013; Revised 21 November 2013; Accepted 26 November 2013

Academic Editor: Tianchang Hu

Copyright (C) 2013 Petr Vlcak et al. This is an open access article distributed under the Creative Commons Attribution License, which permits unrestricted use, distribution, and reproduction in any medium, provided the original work is properly cited.

\begin{abstract}
The ion beam assisted deposition (IBAD) method was chosen for preparing a carbon thin film with a mixing area on a substrate of Ti6Al4V titanium alloy. Nitrogen ions with energy $90 \mathrm{keV}$ were used. These form a broad ion beam mixing area at the interface between the carbon film and the substrate. We investigated the chemical composition by the glow discharge optical emission spectroscopy (GD-OES) method and the phases by the X-ray diffraction (XRD) method. The measured concentration profiles indicate the mixing of the carbon film into the substrate, which may have an effect on increasing the adhesion of the deposited film. The nanohardness and the coefficient of friction were measured. We found that the modified samples had a markedly lower coefficient of friction even after damage to the carbon film, and they also had higher nanohardness than the unmodified samples. The increased nanohardness is attributed to the newly created phases that arose with ion implantation of nitrogen ions.
\end{abstract}

\section{Introduction}

Titanium and titanium alloys have many applications. They are used in the aerospace industry and in biomedical engineering. However, the components of titanium alloys show unsatisfactory tribological properties [1]. The tribological properties of Ti6Al4V titanium alloy have received huge attention worldwide. Many methods and concepts for modifying the coating to reduce the coefficient of friction and the wear rate have been applied. It is known that carbonbased coatings can exhibit a very low coefficient of friction and that their application on a substrate may result in a multiple increase in its working life [2-4]. Due to the high internal stress, these coatings have low adhesion to many substrates $[5,6]$. We therefore investigated various deposition techniques and the parameters of these techniques that influence not only the adhesion but also other properties of carbon-based layers [7-9]. In our work, the ion beam assisted deposition (IBAD) method was chosen for modifying the surface properties of the titanium alloy. A carbon coating a few tens nanometers in thickness was applied to a Ti6Al4V alloy substrate. Subsequent ion bombardment by nitrogen ions with energy $90 \mathrm{keV}$ was aimed at mixing the coating and substrate atoms and hardening the surface area. The parameters of the preparation process were proposed in such a way that the resulting model of the mixed area would have a decreasing concentration towards the substrate. The aim was to investigate the effect of the deposition parameters on the penetration depth of the mixed and implanted atoms and on the surface properties.

\section{Materials and Methods}

2.1. Substrates. The substrate material was a Ti6Al4V titanium alloy with an $\alpha+\beta$ phase microstructure. The chemical composition is shown in Table 1 . The disc samples $(20 \mathrm{~mm}$ in diameter and $6 \mathrm{~mm}$ in thickness) were cut from a titanium alloy bar and were then ground with a series of waterproof abrasive papers up to 2000 grit. Final polishing was performed with $5 \mu \mathrm{m}$ and $1 \mu \mathrm{m}$ diamond paste. The samples were ultrasonically cleaned in isopropyl alcohol before the preparation process. 
TABLE 1: Chemical composition of the Ti6Al4V titanium alloy (wt\%).

\begin{tabular}{ccccccccc}
\hline Element & $\mathrm{C}$ & $\mathrm{V}$ & $\mathrm{Al}$ & $\mathrm{O}$ & $\mathrm{N}$ & $\mathrm{H}$ & $\mathrm{Fe}$ & $\mathrm{Ti}$ \\
\hline Content & 0.10 & $3.50-4.50$ & $5.50-6.75$ & 0.20 & 0.05 & 0.0125 & 0.3 & Balance \\
\hline
\end{tabular}

TABLE 2: Operating parameters of the surface modifications by IBAD.

\begin{tabular}{lc}
\hline Parameter & Values \\
\hline Electron beam deposition of carbon nanolayers & $8 \cdot 10^{-5}$ \\
$\quad$ Base pressure $(\mathrm{Pa})$ & $8 \cdot 10^{-4}$ \\
Work pressure $(\mathrm{Pa})$ & 6 \\
Acceleration voltage $(\mathrm{kV})$ & 100 \\
Emission current $(\mathrm{mA})$ & Graphite $(99.999 \%)$ \\
Target & 0.15 \\
Deposition rate $\left(\mathrm{nm} \cdot \mathrm{s}^{-1}\right)$ & $9 \cdot 10^{-5}$ \\
Nitrogen ion implantation & $5 \cdot 10^{-3}$ \\
Base pressure $(\mathrm{Pa})$ & 90 \\
Work pressure $(\mathrm{Pa})$ & 1.5 \\
Acceleration voltage $(\mathrm{kV})$ & \\
Ion beam current density $\left(\mu \mathrm{A} \cdot \mathrm{cm}^{-2}\right)$ & \\
\hline
\end{tabular}

2.2. Preparation Process. The modifications of the surface properties were performed by the IBAD method. We used the method in which the modifications were created by sequential deposition and ion implantation. A scheme of the IBAD equipment used in the experiment is presented in our previous work [10]. The samples were attached in a vacuum chamber to a water-cooled rotary manipulator. The thickness of the nanolayers was monitored with a quartz monitor, and the ion beam current was measured using a Faraday cup. The temperature of the samples was measured by a thermocouple located in the sample holder. The modifications were created in two steps. First, a carbon nanolayer was deposited by electron beam evaporation of a graphite tablet. The deposition rate of the carbon nanolayers was about $0.15 \mathrm{~nm} \cdot \mathrm{s}^{-1}$, and the work pressure was about $8 \cdot 10^{-4} \mathrm{~Pa}$. In the second step, the coated substrates were irradiated with nitrogen ions. The acceleration voltage was $90 \mathrm{kV}$, and the ion beam current density was about $1.5 \mu \mathrm{A} \cdot \mathrm{cm}^{-2}$. During the deposition and ion implantation process, the temperature of the sample was below $50^{\circ} \mathrm{C}$. The parameters of the deposition and ion implantation process are shown in Table 2. Prior to deposition, the samples in the vacuum chamber were cleaned by low-energy argon bombardment for $30 \mathrm{~min}$. The energy of the accelerated argon ions was $700 \mathrm{eV}$, and the ion beam current density was $90 \mu \mathrm{A} \cdot \mathrm{cm}^{-2}$.

The parameters of the IBAD modified samples (nanolayer thickness and fluence of implanted ions) were proposed according to mathematical models of the carbon and nitrogen concentration profiles simulated by TRIDYN code and SRIM code. The chosen parameters are shown in Table 3.

2.3. Chemical and Structure Analysis of the Surface Area. We investigated the chemical composition by means of the glow discharge optical emission spectroscopy (GD-OES) method [11]. A LECO GDS850A optical emission spectrometer was used. GDS850A is an optical emission spectrometer with a
TABLE 3: Parameters of the IBAD modified samples (thickness of the carbon nanolayer, fluence of the nitrogen ions).

\begin{tabular}{lcccc}
\hline Sample & A & B & C & D \\
\hline Nanolayer thickness $(\mathrm{nm})$ & 20 & 40 & 20 & 40 \\
Fluence $\left(\mathrm{cm}^{-2}\right)$ & $1 \cdot 10^{17}$ & $1 \cdot 10^{17}$ & $5 \cdot 10^{16}$ & $5 \cdot 10^{16}$ \\
\hline
\end{tabular}

Paschen-Runge polychromator with focal length of $750 \mathrm{~mm}$, and it has a glow discharge spectral source with a flat cathode (Grimm type). The sample itself serves as a cathode in this arrangement. Atomization of the sample surface is performed by the mechanism of cathode sputtering under an anomalous discharge. The process gas was argon. The spectrometer was calibrated using reference materials with a known composition and known sputter rates, and the "standard" calibration model was used [12]. The intensities of selected emission lines of the elements of interest are expressed as functions of the product $c_{E, M} \cdot q_{M}$, where $c_{E, M}$ is the concentration of element $E$ in sample $M$ and $q_{M}$ is its sputter rate. In a depth profile analysis of an unknown sample, the intensities of selected lines are recorded as functions of time. The sample composition is subsequently calculated as a function of time. The sum of the concentrations of all the elements is $100 \%$ at each point of the profile, and the unknown sputter rate of the sample was calculated with known emission yields as a function of time. Finally, the time scale was converted into depth by integrating the sputter rate as a function of time.

We investigated the phase composition using the X-ray diffraction (XRD) method. The measurements were performed on a PANalytical X'Pert PRO powder diffractometer. Geometry with the parallel beam with an incident angle of $0.5^{\circ}$ was chosen with respect to the intensity of the diffraction pattern. The diffraction was recorded for the $2 \theta$ range $20^{\circ}-$ $80^{\circ}$. Cobalt radiation with wavelength $0.1789 \mathrm{~nm}$ was used. 
2.4. Nanoindentation and Sliding Tests. The nanohardness of the ion beam modified samples was investigated by nanoindentation testing. The dependence of the nanohardness on the depth was registered. The quasistatic load controlled experiments were performed on a Hysitron TriboIndenter system with a Berkovich diamond tip, using a partial unloading function consisting of 39 cycles, each composed of a loading segment, a dwell, and an unloading segment $(1 \times 1 \times 1$ second) up to a force value of $5000 \mu \mathrm{N}$. Nanoindentation testing proceeded at a temperature of $23.6^{\circ} \mathrm{C}$. Grids of $3 \times$ 4 indents with $10 \mu \mathrm{m}$ separation were applied for each sample. The nanohardness values were determined for each unloading segment of the indentation cycle. The tip area function was calibrated on the fused quartz sample according to a standard calibration procedure [13].

A sliding test was performed in order to find out the coefficient of friction. A pin-on-disc tribometer was used. A constant normal load of $2 \mathrm{~N}$ was set during the test. The radius of rotation was $4 \mathrm{~mm}$, and the velocity was $6 \mathrm{~cm} \cdot \mathrm{s}^{-1}$. The second part of the sliding couple was a $100 \mathrm{Cr} 6$ steel ball $6 \mathrm{~mm}$ in diameter. The sliding tests proceeded at laboratory ambient temperature $23^{\circ} \mathrm{C}$ without lubrication and with relative humidity of $57 \%$. The measurements were performed without sucking off the products of abrasive wear.

The sliding test of the modified samples was supplemented by measurements of the surface condition. An atomic force microscope (AFM) in tapping mode was used to characterize the surface topography.

\section{Results and Discussion}

3.1. Chemical Composition of Surface Area. The chemical composition was investigated by the GD-OES method. Figure 1 shows the resulting concentration profiles of nitrogen and carbon correlated with their mathematical models from the simulation programs. The simulated concentration profiles of carbon were determined by the TRIDYN code [14], and the simulated concentration profiles of nitrogen were determined by the SRIM code [15]. The correspondence between the measured and calculated depth profiles of the carbon distribution is very good. The carbon concentration on the surface is slightly lower than that in the mathematical model of the carbon concentration profile. This may be due to contamination of the surface by the residual atmosphere consisting mainly of nitrogen. Minor differences between the measured and simulated nitrogen concentration profiles are shown in Figure 1.

The experimental concentration profiles are deformed towards the surface in comparison with the mathematical models. A large amount of energy is delivered by nuclear collisions of ions in the surface area. This leads to the formation of point defects. We presume that especially the increased concentration of these defects and their migration lead to deformation of the concentration profiles in this area through radiation enhanced diffusion (RED). Budzynski et al. [16] reported similar deformations of concentration profiles caused by RED. The SRIM simulations do not include the calculation of the dynamic change of the target composition. This has a significant effect on the calculation result, especially at higher fluences. The depth profile of the nitrogen concentration towards the substrate is undoubtedly influenced by the crater effect. A crater is formed during the GD-OES measurement, and sputtering from the crater wall influences the depth profile of the nitrogen concentration. Diffusion may play some role, but the sputtering from the crater wall has the dominant influence. For the samples with lower fluence $\left(5 \cdot 10^{16} \mathrm{~cm}^{-2}\right)$, the maximum nitrogen concentration was found to be approximately 10 at $\%$ at a depth of approximately $75 \mathrm{~nm}$. For the samples with higher fluence $\left(1 \cdot 10^{17} \mathrm{~cm}^{-2}\right)$, the maximum nitrogen concentration was found to be approximately 20 at $\%$ at a depth of approximately $80 \mathrm{~nm}$. The mixing area is well perceptible from the course of the concentration profiles of carbon and titanium in Figure 1. For clarity, the concentration profiles of the alloying elements of the substrate (aluminium and vanadium), which are an addition to $100 \%$ concentration of the Ti6Al4V alloy, are not plotted in Figure 1.

3.2. XRD Analysis. The crystal structure and the phase composition of the modified samples were examined by the XRD method. This method can provide direct evidence of intermetallic compounds formed in the implanted surface area. Alpha structural phase of the titanium alloy $(\alpha-\mathrm{Ti})$ was observed in all samples, while no minority beta structural phase $(\beta-\mathrm{Ti})$ was identified in the diffraction spectra. In the XRD diffractograms, additional $\alpha$-Ti phase with a larger lattice parameter appeared. The implanted nitrogen ions were placed in the interstitial sites, and a solid solution of nitrogen was formed in the titanium matrix. A part of the interstitial nitrogen ions was arranged into the structure, and $\mathrm{TiN}_{x}$ nonstoichiometric phase arose. $\mathrm{TiN}_{0.61}$ phase and graphite were observed for all types of samples. Liu et al. [17] and Schmidt et al. [18] have confirmed that nitrogen ion implantation on Ti-6Al-4V stabilizes the $\alpha$-Ti phase and forms compounds of varying composition and stoichiometry. The diffraction spectra of all types of samples have similar characteristics; see Figure 2.

3.3. Nanoindentation Tests. The indentation hardness was investigated by nanoindentation. The resulting depth profiles of the indentation hardness are shown in Figure 3.

The maximum indentation hardness values of the modified samples are shown in Table 4.

Hardness values at depths below $14 \mathrm{~nm}$ should be excluded from the depth profiles in Figure 3. The results in this region are influenced by the error originating from standard calibration of the tip area function on fused quartz [13]. The indentation hardness values decrease with increasing contact depth and converge to the hardness of the reference sample within the indentation depth. All samples modified by the ion beam assisted deposition method with the proposed technological parameters had a more than twofold increase in indentation hardness compared to the unmodified substrate. The increase in indentation hardness can be attributed mainly to nitrogen ion implantation. Hard titanium nitrides detected by XRD in the titanium matrix hardened the surface area. Although XRD analysis showed no carbidic phase, it can be assumed that the mixing area may also have an impact on the 


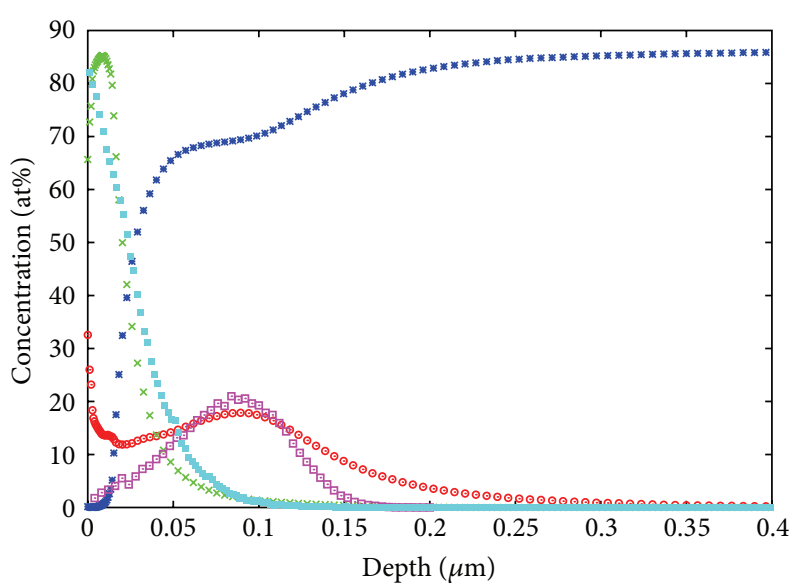

(a)

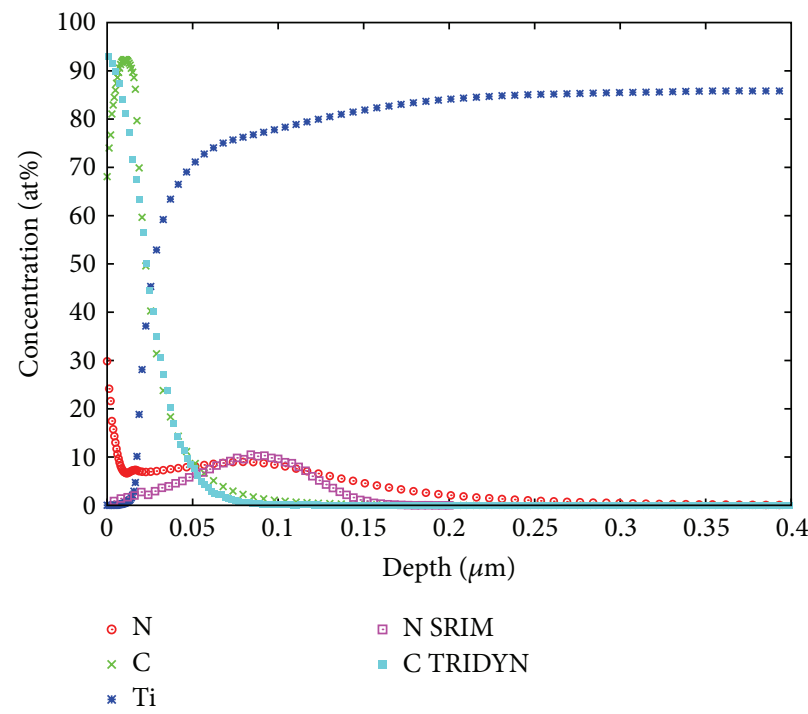

(c)

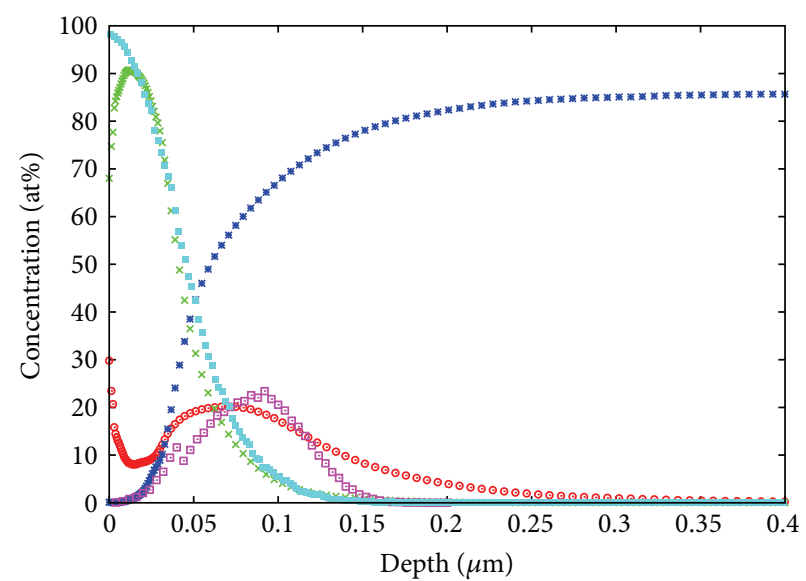

(b)

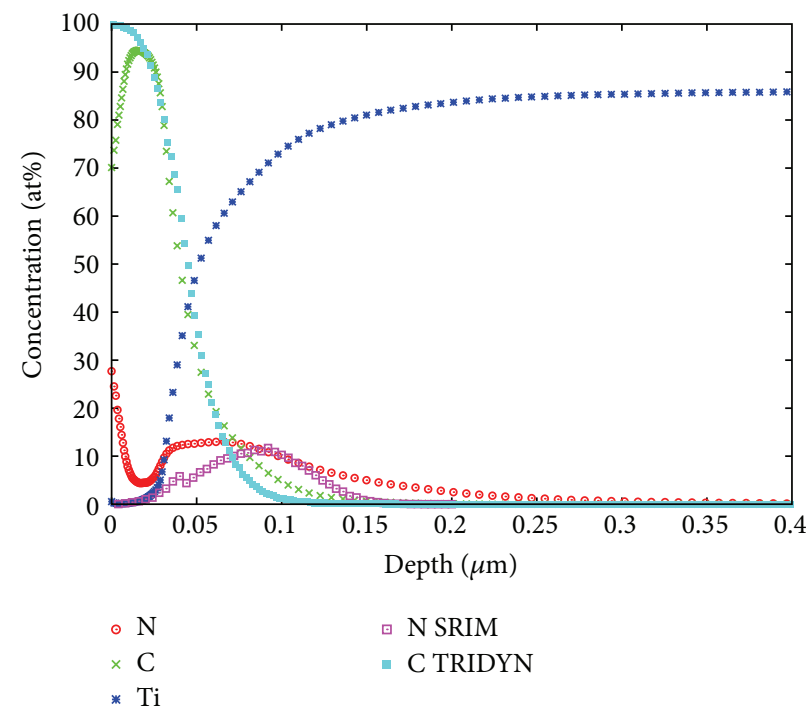

(d)

FIgURE 1: Chemical composition of the surface area of the samples with a carbon nanolayer implanted by nitrogen ions-(a) C $20 \mathrm{~nm}$, $1 \cdot 10^{17} \mathrm{~cm}^{-2}$, (b) C $40 \mathrm{~nm}, 1 \cdot 10^{17} \mathrm{~cm}^{-2}$, (c) C $20 \mathrm{~nm}, 5 \cdot 10^{16} \mathrm{~cm}^{-2}$, and (d) C $40 \mathrm{~nm}, 5 \cdot 10^{16} \mathrm{~cm}^{-2}$. Experimental concentration profiles of carbon (C) and nitrogen (N) compared with the simulated concentration profiles of carbon (C TRIDYN) and nitrogen (N SRIM).

increase in indentation hardness. The indentation hardness results in Figure 3 contain the depth profile of the indentation hardness of the coated sample without ion implantation. The maximum hardness value of the sample coated with a carbon nanolayer of $40 \mathrm{~nm}$ without ion implantation is $6.3 \mathrm{GPa}$ at a depth of $14 \mathrm{~nm}$. The nonconstant course of the indentation hardness of the unmodified substrate is caused by mechanical strengthening of the surface due to cutting and polishing of the samples.

3.4. Sliding Tests. Sliding tests were carried out on a pin-ondisc tribometer, and the results are shown in Figure 4.

Figure 4 shows the evolution of the coefficient of friction for all ion beam modified samples as a function of the number of cycles. The friction curves of the modified samples can be divided into two parts. The first part represents the low-friction regime, while the second part represents the increased friction regime. The friction coefficient in the lowfriction part is very low, having a value of about 0.1 (Figures 4(a), 4(b), and 4(c)) which is typical for DLC (diamondlike carbon) coatings [19]. The low level of the coefficient of friction is explained by the thin carbon film, which remained on the surface after ion implantation, as shown by the results of the previous analysis of the chemical composition (see Figure 1). The friction coefficient for modifications with a $20 \mathrm{~nm}$ carbon nanolayer and both applied fluences remains low in the next 1000 cycles; and for modification with a $40 \mathrm{~nm}$ carbon nanolayer and fluence $1 \cdot 10^{17} \mathrm{~cm}^{-2}$, it remains low in the next 3500 cycles; that is, a two times thicker nanolayer increased the duration of the lubrication effect by a factor of 3.5. The low-friction coefficient value remained constant until the carbon nanolayer was destroyed. The hard titanium nitrides detected by XRD in the titanium matrix hardened the surface area after nitrogen ion implantation, 
TABLE 4: Maximum indentation hardness values of the modified samples and the reference sample.

\begin{tabular}{|c|c|c|c|c|c|}
\hline Sample & $\begin{array}{c}\text { REF } \\
\text { (unmodified) }\end{array}$ & $\begin{array}{c}\mathrm{A} \\
\left(\mathrm{C} 20 \mathrm{~nm} / 1 \cdot 10^{17} \mathrm{~cm}^{-2}\right)\end{array}$ & $\begin{array}{c}\mathrm{B} \\
\left(\mathrm{C} 40 \mathrm{~nm} / 1 \cdot 10^{17} \mathrm{~cm}^{-2}\right)\end{array}$ & $\begin{array}{c}\mathrm{C} \\
\left(\mathrm{C} 20 \mathrm{~nm} / 5 \cdot 10^{16} \mathrm{~cm}^{-2}\right)\end{array}$ & $\begin{array}{c}\mathrm{D} \\
\left(\mathrm{C} 40 \mathrm{~nm} / 5 \cdot 10^{16} \mathrm{~cm}^{-2}\right)\end{array}$ \\
\hline $\begin{array}{l}\text { Maximum } \\
\text { indentation } \\
\text { hardness } \\
\text { (GPa) }\end{array}$ & 5.3 & 13 & 12.4 & 11.2 & 11.5 \\
\hline $\begin{array}{l}\text { Indentation } \\
\text { depth }(\mathrm{nm})\end{array}$ & 14 & 15 & 15 & 14.6 & 19.6 \\
\hline
\end{tabular}

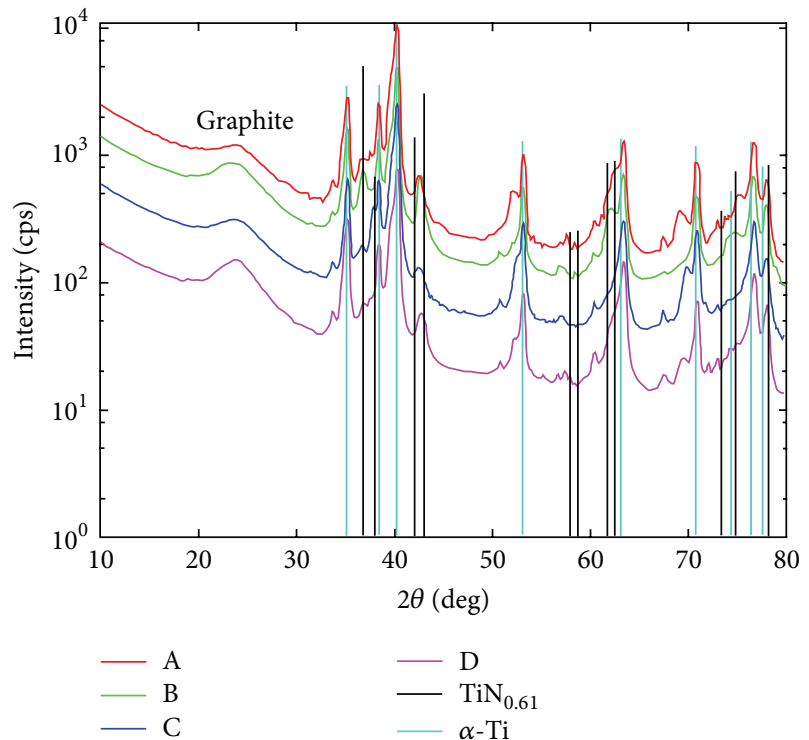

FIgURE 2: Diffraction spectra of the modified samples-(A) C $20 \mathrm{~nm}, 1 \cdot 10^{17} \mathrm{~cm}^{-2}$, (B) C $40 \mathrm{~nm}, 1 \cdot 10^{17} \mathrm{~cm}^{-2}$, (C) C $20 \mathrm{~nm}$, $5 \cdot 10^{16} \mathrm{~cm}^{-2}$, and (D) C $40 \mathrm{~nm}, 5 \cdot 10^{16} \mathrm{~cm}^{-2}$.

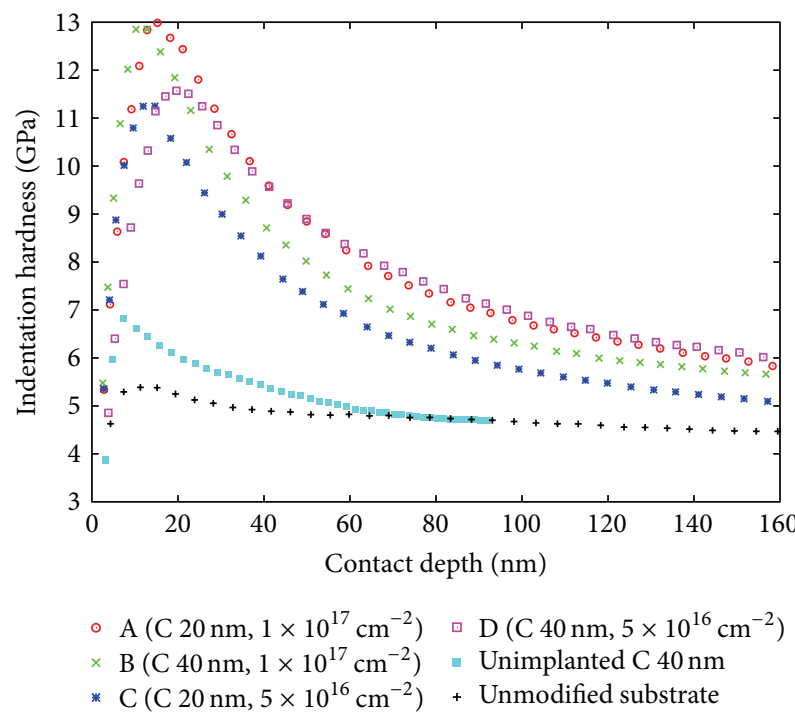

FIGURE 3: Depth profiles of the indentation hardness of the modified samples. as shown by the depth profiles of the indentation hardness. The carbon film on the hardened surface acted as a solid lubricant. Almost identical friction curves were obtained for the modifications with the $20 \mathrm{~nm}$ carbon nanolayer and for both applied fluences. The measurements of samples with a $20 \mathrm{~nm}$ carbon nanolayer showed no effect of the fluence on the course of the friction coefficient. The low-friction part was absent for the sample with a $40 \mathrm{~nm}$ carbon nanolayer and applied fluence $5 \cdot 10^{16} \mathrm{~cm}^{-2}$. For the sample with a thicker nanolayer, nitrogen impurity accumulated in the mixing area and the lower nitrogen concentration in the titanium matrix generated lower hardness. The lower hardness of the substrate caused the thicker carbon nanolayer to break, and an increase in the coefficient of friction occurred just at the beginning of the measurement. The thinner nanolayer did not break, because the maximum nitrogen concentration is in the titanium matrix, and the nanolayer is more flexible. The part with increased friction is characterized by a sharp increase in the coefficient of friction. In all samples, the coefficient of friction is approximately 0.28 in this part and is constant until the end of the test. This means a two times greater decrease in the friction coefficient in comparison with the unmodified substrate, which has a coefficient of friction of 0.6 . The resulting reduction in the friction coefficient is attributed to the sliding properties of the mixing area. According to Budzynski et al. [16], implanting nitrogen ions into Ti6Al4V does not cause such a significant reduction in the coefficient of friction without the lubrication effect of a sliding layer.

Three-dimensional AFM images of the selected samples (unmodified substrate and modified sample with a $20 \mathrm{~nm}$ carbon nanolayer and applied fluence $1 \cdot 10^{17} \mathrm{~cm}^{-2}$ ) are shown in Figures 5(a) and 5(b). The scanning area was 20 $\times 20 \mu \mathrm{m}^{2}$. It can be seen that the surface topography of the modified sample and the unmodified substrate are almost the same. Nevertheless, ion beam modifications slightly smoothed down the surface roughness. The surface of the substrate was very smooth, with visible deep depressions. The deep depressions may also be a source of premature failure of the carbon nanolayer. In the case of high concentrations of these depressions, the depressions could be a source of graphite lubricant and could thus reduce the friction.

\section{Conclusion}

The results of chemical composition analysis indicate that the proposed parameters of the modification process lead to the mixing area. The carbon nanolayer remained on the 


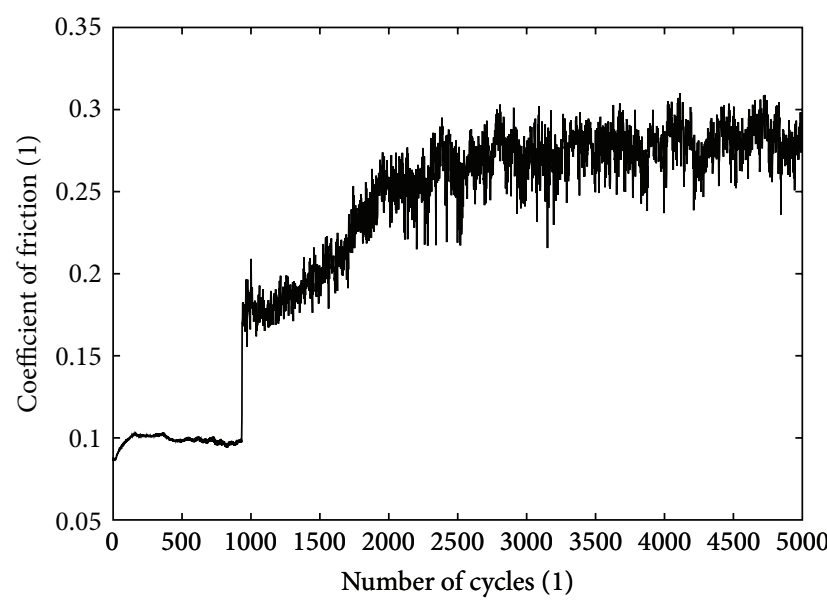

(a)

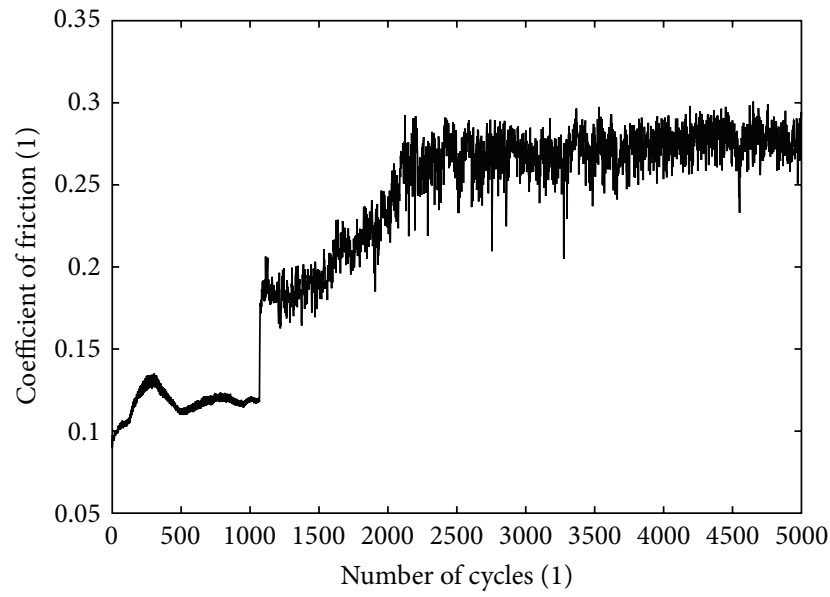

(c)

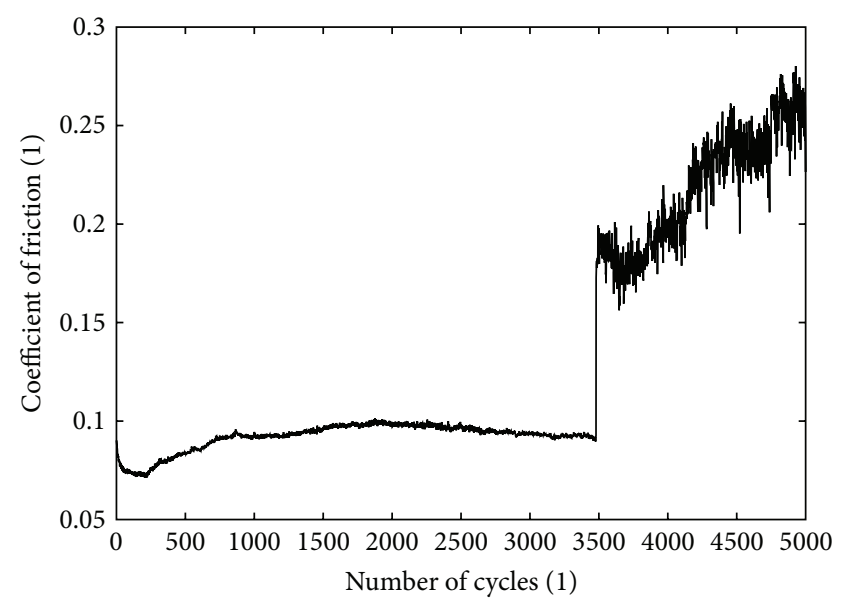

(b)

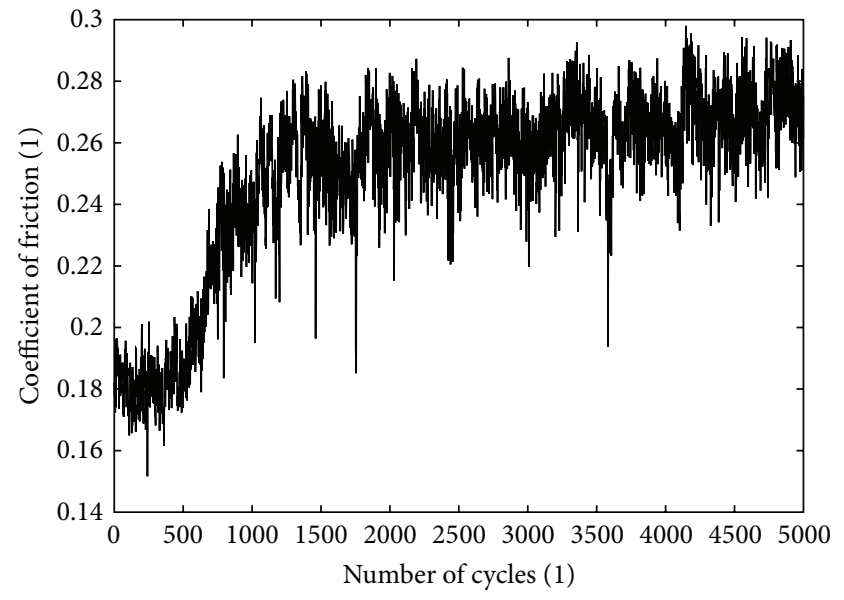

(d)

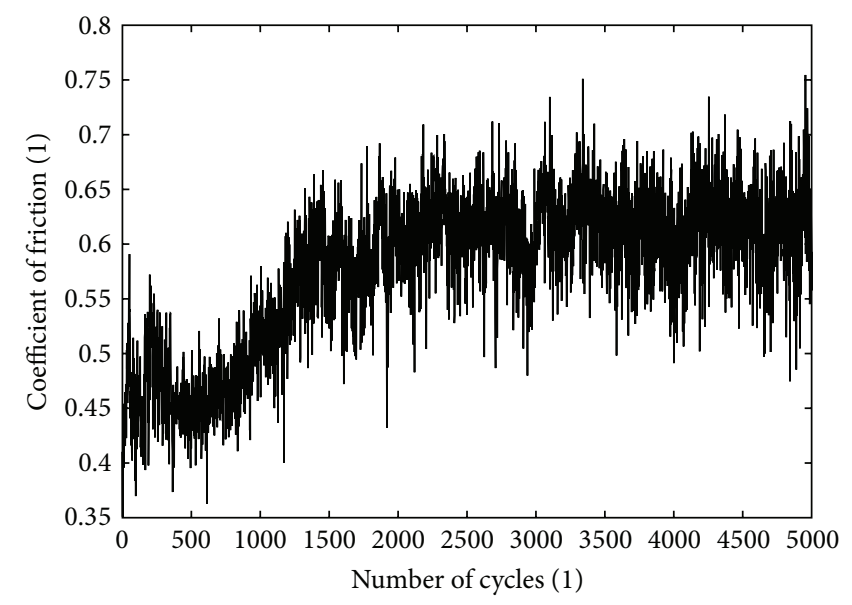

(e)

FIGURE 4: Results of sliding tests of the samples with a carbon nanolayer implanted by nitrogen ions-(a) C $20 \mathrm{~nm}, 1 \cdot 10^{17} \mathrm{~cm}^{-2},(\mathrm{~b}) \mathrm{C} 40 \mathrm{~nm}$, $1 \cdot 10^{17} \mathrm{~cm}^{-2}$, (c) C $20 \mathrm{~nm}, 5 \cdot 10^{16} \mathrm{~cm}^{-2}$, (d) C $40 \mathrm{~nm}, 5 \cdot 10^{16} \mathrm{~cm}^{-2}$, and (e) unmodified substrate.

surface after ion implantation, and this had an influence on the sliding properties. The differences between the measured concentration profiles and the simulated profiles are attributed in particular to the influence of radiation enhanced diffusion, that is, diffusion accelerated by radiation defects.
The results show that the increase in the indentation hardness is primarily the result of nitrogen ion implantation. The hard titanium nitrides detected in the surface area are probably the dominant source of higher hardness. The measurements showed a slight increase in the indentation 
Ref-M3-20 $\mu \mathrm{m} . \mathrm{mdt} \# 1$
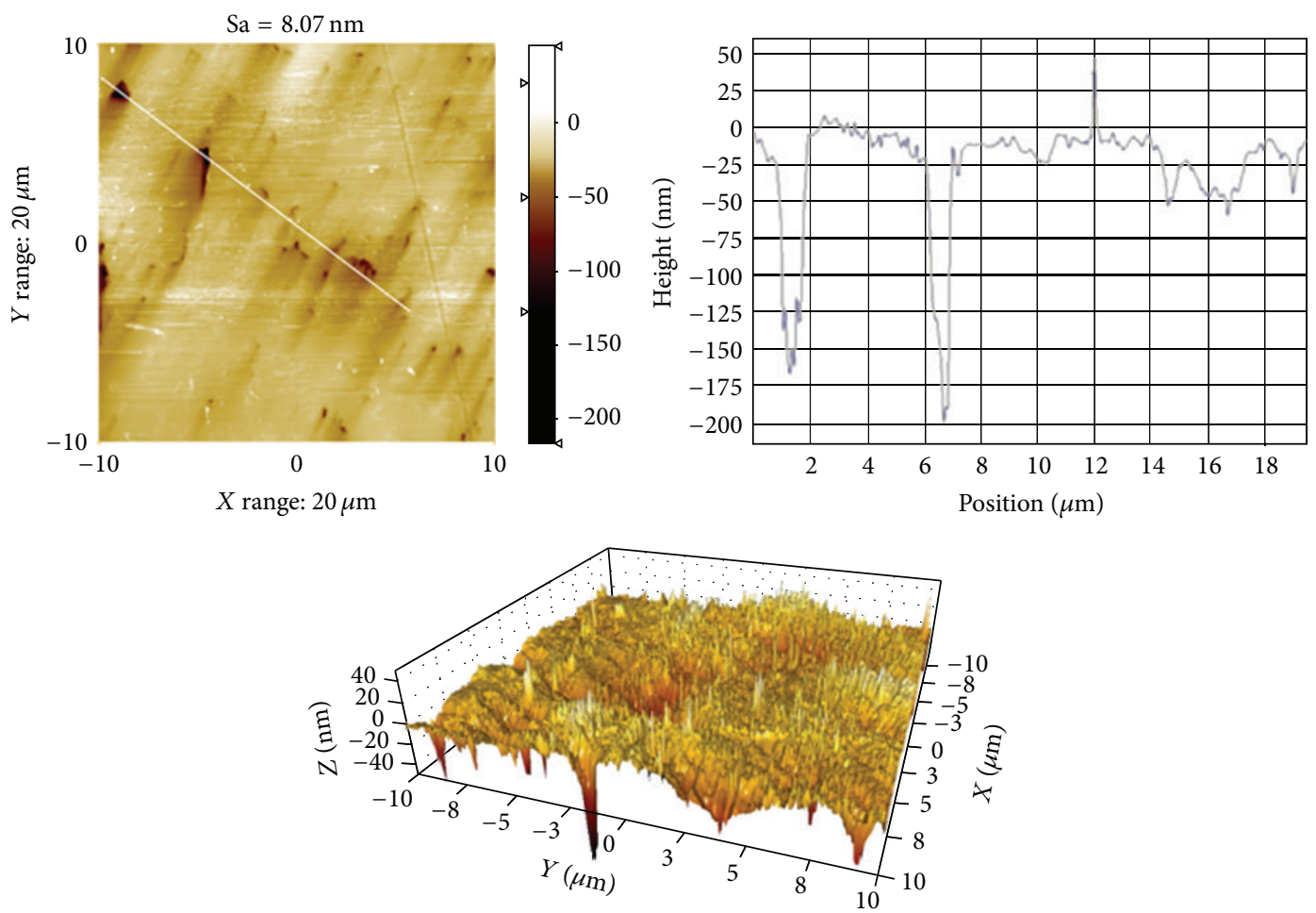

(a)

C-M2-20 $\mu \mathrm{m}$.mdt \#1
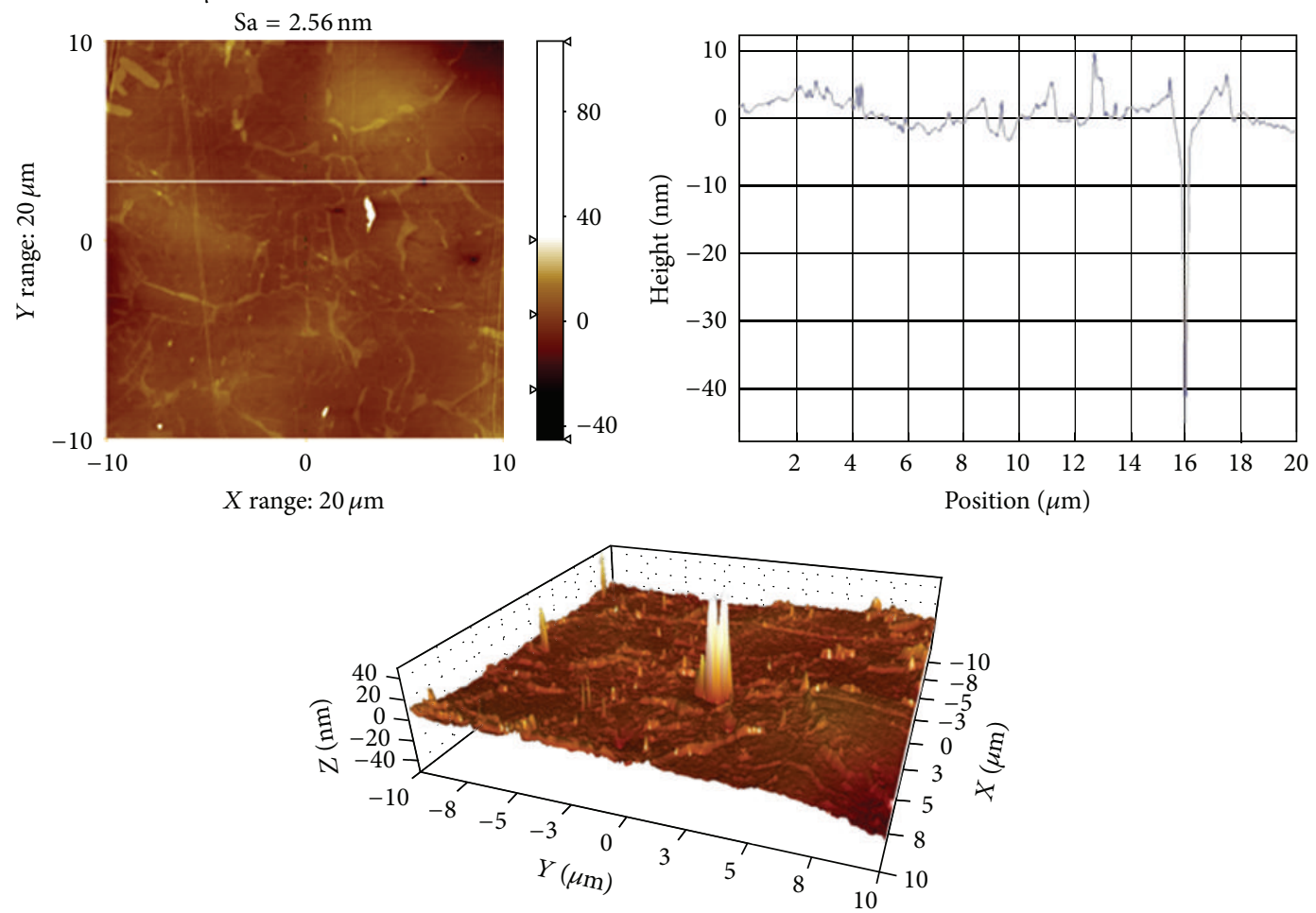

(b)

Figure 5: AFM images of selected samples (a) unmodified substrate and (b) a modified sample with a 20 nm carbon nanolayer and applied fluence $1 \cdot 10^{17} \mathrm{~cm}^{-2}$. 
hardness of the coated sample without ion implantation. The carbon nanolayer may make some contribution to the increase in hardness.

The results of the sliding test indicate that the carbon nanolayer greatly decreased the friction coefficient. The nanolayer on the hardened surface acted as a solid lubricant. Although damage to this nanolayer increased the friction coefficient, its value was lower than the friction coefficient of the unmodified substrate. Double reduction of the friction coefficient was observed. This fact leads to the conclusion that the friction coefficient can be considerably reduced by forming a mixing area. In order to form the mixing area without a residual carbon layer, it is necessary to modify the proposed IBAD deposition parameters.

\section{Acknowledgment}

This research has been supported by the Ministry of Education, Youth and Sports of the Czech Republic, Project SGS OHK2-033-13 of the Czech Technical University in Prague.

\section{References}

[1] M. Geetha, A. K. Singh, R. Asokamani, and A. K. Gogia, "Ti based biomaterials, the ultimate choice for orthopaedic implants-a review," Progress in Materials Science, vol. 54, no. 3, pp. 397-425, 2009.

[2] S. Wei, T. Shao, and P. Ding, "Improvement of orthodontic friction by coating archwire with carbon nitride film," Applied Surface Science, vol. 257, no. 24, pp. 10333-10337, 2011.

[3] S.-W. Jiang, B. Jiang, Y. Li, Y.-R. Li, G.-F. Yin, and C.-Q. Zheng, "Friction and wear study of diamond-like carbon gradient coatings on Ti6Al4V substrate prepared by plasma source ion implant-ion beam enhanced deposition," Applied Surface Science, vol. 236, no. 1-4, pp. 285-291, 2004.

[4] D. Sheeja, B. K. Tay, S. M. Krishnan, and L. N. Nung, "Tribological characterization of diamond-like carbon (DLC) coatings sliding against DLC coatings," Diamond and Related Materials, vol. 12, no. 8, pp. 1389-1395, 2003.

[5] S. Neuville and A. Matthews, "A perspective on the optimisation of hard carbon and related coatings for engineering applications," Thin Solid Films, vol. 515, no. 17, pp. 6619-6653, 2007.

[6] L. F. Bonetti, G. Capote, L. V. Santos, E. J. Corat, and V. J. Trava-Airoldi, "Adhesion studies of diamond-like carbon films deposited on Ti6Al4V substrate with a silicon interlayer," Thin Solid Films, vol. 515, no. 1, pp. 375-379, 2006.

[7] Y. Ren, I. Erdmann, B. Küzün, F. Deuerler, and V. Buck, "Effect of deposition parameters on wear particle size distribution of DLC coatings," Diamond and Related Materials, vol. 23, pp. 184188, 2012.

[8] M. C. Salvadori, F. S. Teixeira, W. W. R. Araújo, L. G. Sgubin, and I. G. Brown, "Interface tailoring for adhesion enhancement of diamond-like carbon thin films," Diamond and Related Materials, vol. 25, no. 6, pp. 8-12, 2012.

[9] V. J. Trava-Airoldi, L. F. Bonetti, G. Capote, L. V. Santos, and E. J. Corat, "A comparison of DLC film properties obtained by r.f. PACVD, IBAD, and enhanced pulsed-DC PACVD," Surface and Coatings Technology, vol. 202, no. 3, pp. 549-554, 2007.

[10] P. Vlcak, F. Cerny, Z. Tolde, J. Sepitka, I. Gregora, and S. Danis, "Mechanical and tribological properties of carbon thin film with tungsten interlayer prepared by ion beam assisted deposition," Journal of Materials, vol. 2013, Article ID 630156, 4 pages, 2013.

[11] R. K. Marcus and J. A. C. Broekaert, Glow Discharge Plasmas in Analytical Spectroscopy, John Wiley \& Sons, Chichester, UK, 2003.

[12] Z. Weiss, "Emission yields and the standard model in glow discharge optical emission spectroscopy: links to the underlying physics and analytical interpretation of the experimental data," Spectrochimica Acta B, vol. 61, no. 2, pp. 121-133, 2006.

[13] W. C. Oliver and G. M. Pharr, "An improved technique for determining hardness and elastic modulus using load and displacement sensing indentation experiments," Journal of Materials Research, vol. 7, no. 6, pp. 1564-1580, 1992.

[14] A. Arranz and C. Palacio, "Ion beam mixing of Ti/Al interfaces by nitrogen irradiation," Surface Science, vol. 601, no. 18, pp. 4510-4514, 2007.

[15] N. Berrouachedi, M. Bouslama, A. Abdellaoui et al., "Investigation by EELS and TRIM simulation method of the interaction of $\mathrm{Ar}^{+}$and $\mathrm{N}^{+}$ions with the InP compound," Applied Surface Science, vol. 256, no. 1, pp. 21-26, 2009.

[16] P. Budzynski, A. A. Youssef, and J. Sielanko, "Surface modification of Ti-6Al-4V alloy by nitrogen ion implantation," Wear, vol. 261, no. 11-12, pp. 1271-1276, 2006.

[17] Y. Z. Liu, X. T. Zu, S. Y. Qiu et al., "Phase formation and modification of corrosion property of nitrogen implanted Ti-Al-V alloy," Vacuum, vol. 81, no. 1, pp. 71-76, 2006.

[18] H. Schmidt, A. Schminke, M. Schmiedgen, and B. Baretzky, "Compound formation and abrasion resistance of ion-implanted Ti6Al4V," Acta Materialia, vol. 49, no. 3, pp. 487-495, 2001.

[19] A. J. Gant, M. G. Gee, and L. P. Orkney, "The wear and friction behaviour of engineering coatings in ambient air and dry nitrogen," Wear, vol. 271, no. 9-10, pp. 2164-2175, 2011. 

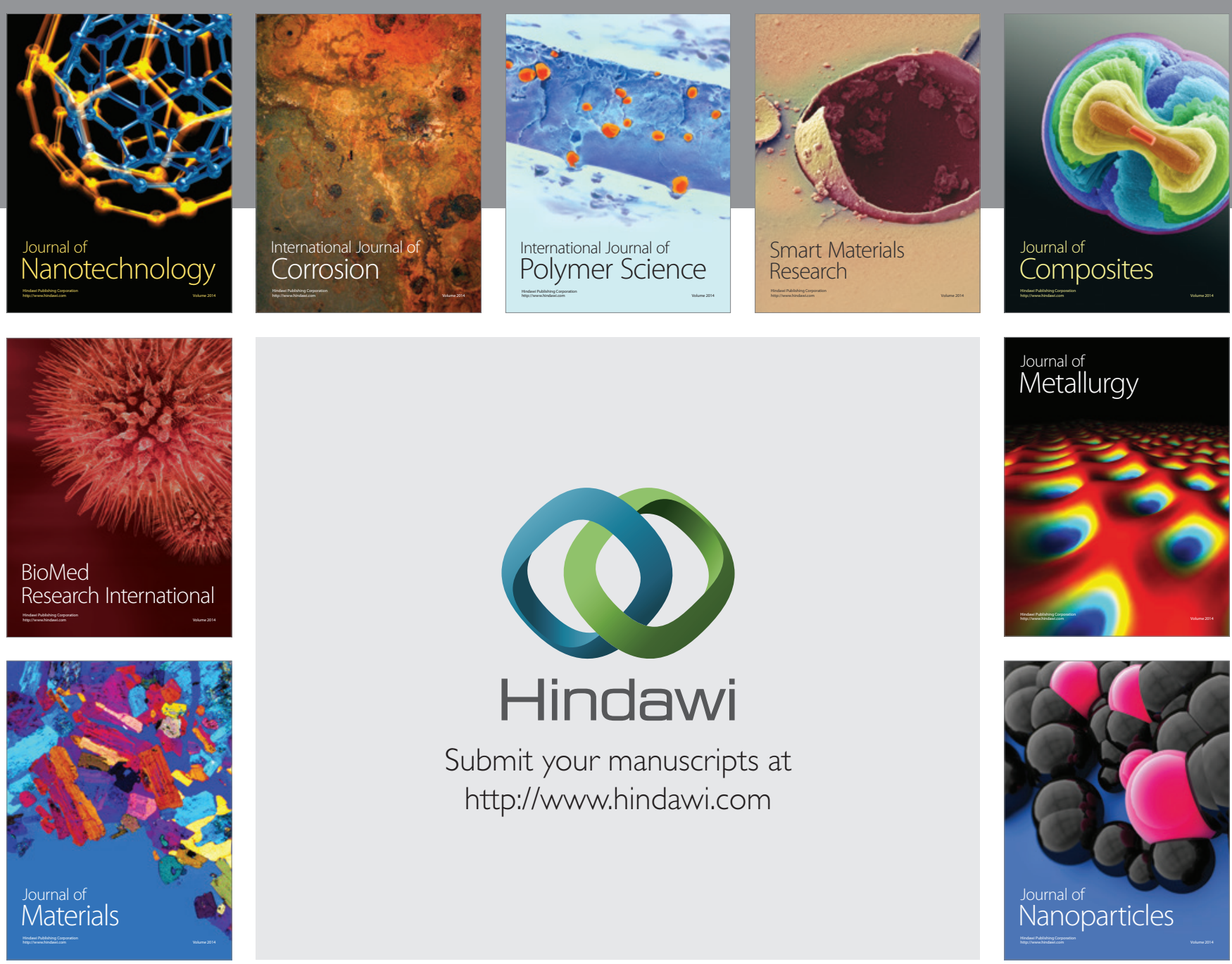

Submit your manuscripts at http://www.hindawi.com
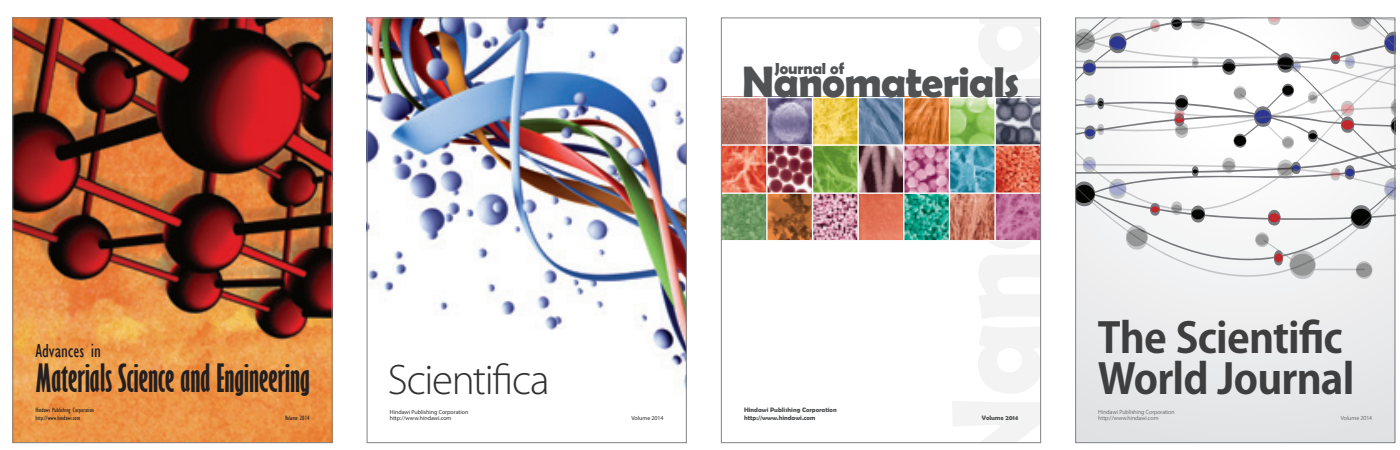

\section{The Scientific World Journal}
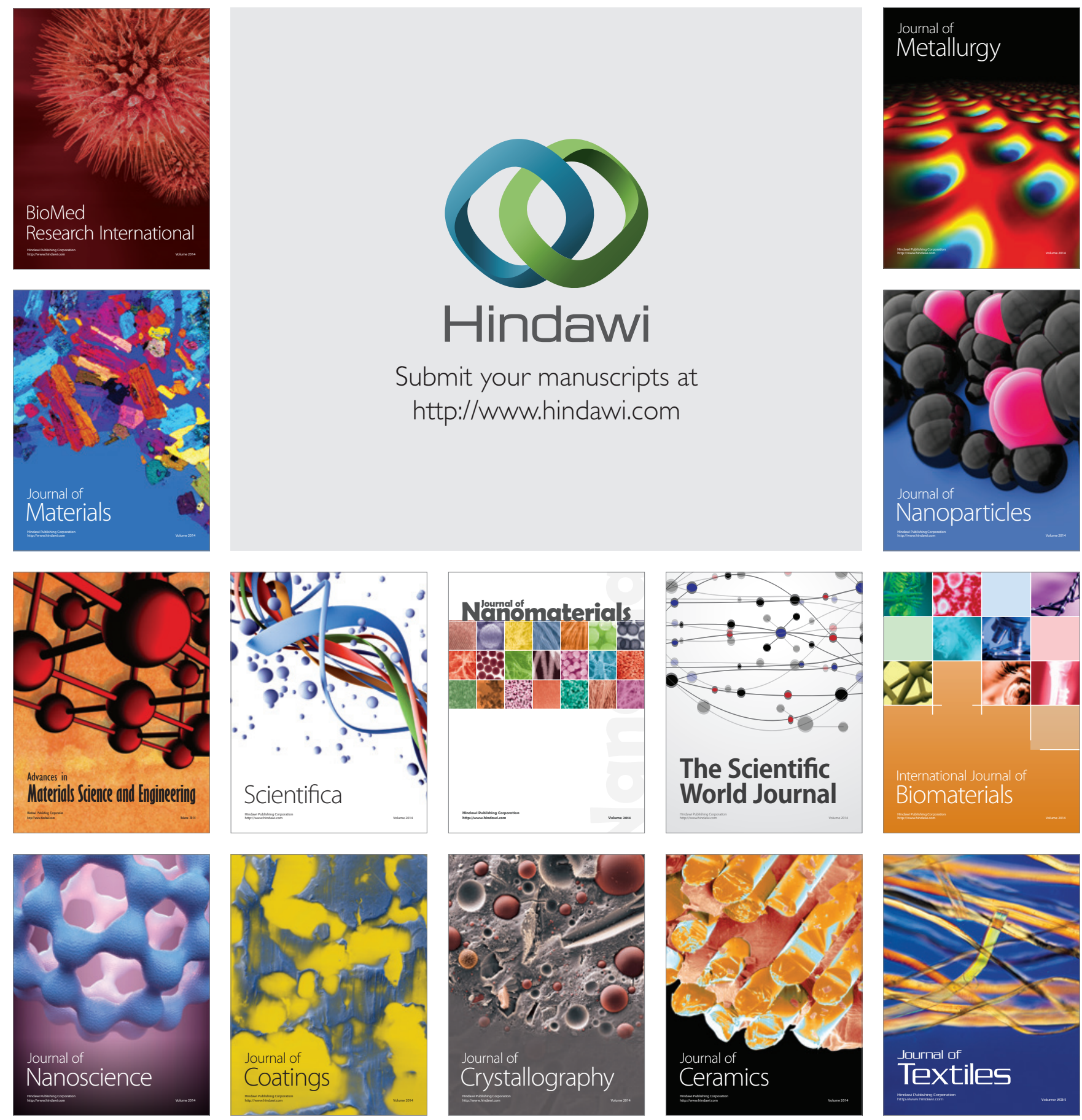